\title{
Age-Related Changes in Neuronal Nicotinic Acetylcholine Receptor Subunit $\alpha 4$ Expression Are Modified by Long-Term Nicotine Administration
}

\author{
Scott W. Rogers, ${ }^{1}$ Lorise C. Gahring, ${ }^{1}$ Allan C. Collins, ${ }^{2}$ and Michael Marks ${ }^{2}$ \\ 1 Salt Lake City Veterans Affairs Medical Center, Geriatric Research, Education, and Clinical Center, and the University of \\ Utah School of Medicine, Salt Lake City, Utah 84112, and 2University of Colorado, Institute for Behavioral Genetics, \\ Boulder, Colorado 80309
}

The distribution of the neuronal nicotinic acetylcholine receptor subunit $\alpha 4$ (nAChR $\alpha 4$ ) in the brains of young (2-4 months) or aged (24-28 months) CBA/J mice was examined using immunohistochemical staining. Anti-nAChR $\alpha 4$ immunoreactivity corresponded with $\mathrm{nAChR} \alpha 4$ RNA expression and high-affinity $\left[{ }^{3} \mathrm{H}\right]$ nicotine binding. Immunostaining in aged mice relative to that in young animals was diminished in the medial septum and diagonal band but was unchanged in the globus pallidus and substantia nigra. The staining of neurons was almost completely absent in the hippocampus of aged animals. The oral administration of nicotine to aged animals for 6 weeks did not alter $\mathrm{nAChR} \alpha 4$ expression relative to that in aged controls.
However, the long-term delivery of nicotine (11 months) to 14-month-old animals corresponded with the highly specific preservation of $\mathrm{nAChR} \alpha 4$ expression in some neurons of the dentate gyrus region and in neurite processes of remaining neurons of the hippocampal CA1 region. These results support the conclusion that the loss of $\mathrm{nAChR} \alpha 4$ expression occurs in key cholinergic regions during normal aging. Furthermore, sustained long-term nicotine delivery may promote highly regionspecific retention of $\mathrm{nAChR}$ expression, but only if initiated before normal age-related receptor decline.

Key words: nicotine; acetylcholine; receptors; aging; neurobiology; mammal
Changes in the expression of nicotinic-cholinergic neurotransmitter receptor systems have been implicated in the onset of age-related brain dysfunction. For example, the cholinergic hypothesis of dementia is based on the well established damage to or loss of cholinergic neurons of the forebrain as reflected by the dramatic loss of cholinergic system markers including acetylcholine transferase or acetylcholine esterase (e.g., see Shroder et al., 1991; Giacobini, 1992). Even during normal aging, in which many of the symptoms of cholinergic depletion are not manifested until later in life (i.e., older than 80 years), there is an age-associated diminished expression of high-affinity $\left[{ }^{3} \mathrm{H}\right]$ nicotine ligand binding sites (Whitehouse et al., 1986, 1988; Kellar et al., 1987, 1989; Shroder et al., 1991; Giacobini, 1992). In addition to the depletion in humans, the normal age-dependent depletion of $\left[{ }^{3} \mathrm{H}\right]$ nicotine binding sites also occurs in the rodent brain (Araujo et al., 1990; Zhang et al., 1990; Schulz et al., 1993; Flood and Coleman, 1996). Consequently, the loss of these sites in the aging mammalian brain should coincide with the loss or change in the expression of subunit proteins that compose these receptors.

The family (see Sargent, 1993; Lindstrom, 1996) of related cDNAs that encode mammalian neuronal nicotinic acetylcholine receptors (nAChRs) includes at least seven $\alpha$-like subunits $(\alpha 2$, $\alpha 3, \alpha 4, \alpha 5, \alpha 6, \alpha 7$, and $\alpha 9$ ) (Elgoyhen et al., 1994) and three $\beta$-like subunits $(\beta 2, \beta 3$, and $\beta 4)$. Mature receptors are composed of

\footnotetext{
Received Feb. 2, 1998; revised April 6, 1998; accepted April 13, 1998.

These studies were supported by Veterans Administration Merit funding to S.W.R. and L.C.G. and by National Institutes of Health Grants AG04418 and DA03194 and Research Scientist Award DA00197 to A.C.C. We gratefully note the outstanding technical assistance of Rachael Kulmer and Robert Simmons.

Correspondence should be addressed to Dr. Scott W. Rogers, Building 533, Room 2410, University of Utah, Salt Lake City, UT 84112.

Copyright (C) 1998 Society for Neuroscience $\quad 0270-6474 / 98 / 184825-08 \$ 05.00 / 0$
}

pentameric combinations of these subunits that impart to these ion channels their distinct functional properties. The expression of these subunits is in part regulated transcriptionally because each is expressed in unique, but overlapping, brain regions (see Deneris et al., 1991; Marks et al., 1992). Post-transcriptional mechanisms also influence receptor expression because the administration of nicotine to rodents [either in their drinking water or by direct infusion into the brain (Marks et al., 1985, 1991, 1992; Kellar et al., 1989; Collins et al., 1996; Booker and Collins, 1997)] increases the binding of $\left[{ }^{3} \mathrm{H}\right]$ nicotine by as much as threefold without changing subunit transcript numbers (Marks et al., 1992). The principal receptor subunit combination that composes the high-affinity $\left[{ }^{3} \mathrm{H}\right]$ nicotine binding site in both mammals and chickens consists of subunits $\alpha 4$ and $\beta 2$ (Anand et al., 1991; Whiting et al., 1991; Flores et al., 1992, 1996). Furthermore, immunoprecipitation of $\mathrm{nAChR} \alpha 4$ or $\mathrm{nAChR} \beta 2$ accounts for $>80 \%$ of the increase in high-affinity ligand binding after chronic nicotine administration (Flores et al., 1992, 1996). When only these two subunits are expressed in transfected cells, high-affinity ligand binding sites are created, and they can also be upregulated by a nicotine-related decrease in receptor degradation (Whiting et al., 1991; Peng et al., 1997). Because the $\mathrm{nAChR} \beta 2$ subunit is widely expressed in the nervous system (Swanson et al., 1987; Deneris et al., 1988, 1991; Hill et al., 1993) and exhibits relatively little selectivity in associating with other $\mathrm{nAChR} \alpha$ subunits (e.g., Boulter et al., 1987; Deneris et al., 1991; Flores et al., 1992, 1996; Lindstrom, 1996), the detailed examination of immunoreactivity to the $\mathrm{nAChR} \alpha 4$ subunit was selected to reflect most accurately the expression of this receptor in the rodent brain.

The possibility that chronic exposure to nicotinic pharmacological agents and the subsequent upregulation of ligand binding sites may be exploited as a therapeutic strategy to combat age- 
associated cognitive decline has gained considerable interest (e.g., Nicholson, 1994). Taken together with the above reports, determining whether acute or long-term nicotine administration alters the distribution or expression of $\mathrm{nAChR} \alpha 4$ is an important first step in this assessment. We have used antibodies to the $\mathrm{nAChR} \alpha 4$ subunit to examine the distribution and expression of immunoreactivity to this subunit in the brains from young (3-4 months) $\mathrm{CBA} / \mathrm{J}$ mice and compared this pattern of expression with that observed in the aged (24-27 months) CBA/J brain. In addition, we have examined anti-nAChR $\alpha 4$ immunoreactivity after the oral administration of nicotine to aged animals for 6 weeks and to adult animals (14 months) for 11 months.

\section{MATERIALS AND METHODS}

Antibodies. The preparation of rabbit polyclonal anti-nAChR $\alpha 4$ subunit antisera has been described previously (Rogers et al., 1991a,b, 1992; Flores et al., 1992, 1996; Cauley et al., 1996). Immunogen in the rabbits designated 5008 or 5009 was a portion of the cytoplasmic domain of rat nAChR $\alpha 4$ expressed as a fusion protein in bacteria (Rogers et al., 1991a,b; Flores et al., 1992).

Mouse strain, fixation, and immunohistochemistry. CBA/J mice were obtained through the National Institute on Aging. Mice were perfused with fixative, and free-floating brain sections were prepared and stained as described elsewhere (Gahring et al., 1996). Rabbit anti-nAChR $\alpha 4$ polyclonal serum was added at a $1: 1000$ dilution overnight at $4^{\circ} \mathrm{C}$ with gentle rocking; the sections again were washed with PBS, and secondary goat anti-rabbit peroxidase (Jackson Immunolaboratories) was added at a 1:750 dilution in blocking PBS for $1 \mathrm{hr}$ at room temperature. Immunoreactivity was revealed by adding diaminobenzidine (DAB; $100 \mu \mathrm{g} / \mathrm{ml}$ ) and $\mathrm{H}_{2} \mathrm{O}_{2}(0.0001 \%)$ in PBS to the sections at room temperature with gentle rocking. Sections were washed with PBS to stop development, mounted on microscope slides, and coverslipped before analysis.

Data analysis. Serial sections were mounted on microscope slides for imaging and subsequent analysis. In all cases, six to eight fields including both ipsilateral and contralateral regions from the same relative anatomical level were digitized and used for quantitative comparisons with Image-Pro Plus software (Media-Cybernetics). For each animal, at least three sections were scored bilaterally for immunoreactivity. Double-label experiments (data not shown) included rabbit anti-nAChR $\alpha 4$ antiserum, and either mouse anti-neurofilament antibody (Sigma, St. Louis, MO; or Boehringer Mannheim, Indianapolis, IN), anti-glial fibrillary acidic protein (Boehringer Mannheim), or rat monoclonal mAB299 to antinAChR $\alpha 4$ (Research Biochemicals, Natick, MA) confirmed neuronal staining and concordance between reagents. No cells were detected that colabeled with anti-nAChR $\alpha 4$ and anti-glial fibrillary acidic protein (Sigma) (data not shown). All anatomical regions were defined as described by Franklin and Paxinos (1997).

For quantitative analysis, immunopositive cells were defined as those exhibiting somal staining, and only cells with a stained unit area sufficient to ensure that the majority of their volume was contained within the section were scored. Values for each region and from each animal were collected and summed, and an average was derived for each age or treatment group. Both cell number per anatomically defined region and cell number per unit area were calculated. In our experience, both values gave similar results; however, because of the possibility that section mounting to glass slides and poststaining dehydration could alter the unit area measure, we have selected to report our results in terms of immunopositive cells per region. Statistical analyses were applied to indicate the relative significance of differences between different regions of the young and aged brain as reported in the text for each experiment using either the Student's $t$ test, ANOVA, or the Mann-Whitney rank sums nonparametric statistical test. The best use of statistical approaches is somewhat unclear in these studies. Although we draw on a random population of young or aged animals available through the National Institute on Aging, we cannot be certain that aged animals actually represent a statistically defined normal population. For example, the analysis of humans that live to be 100 years of age does not necessarily reflect the physical or mental conditions "typical" of an aged population, particularly because the majority of aged individuals have already died. Therefore, although the young or adult population would be expected to be drawn from a "normal" population, caution must be exercised when assuming this for the aged population. Consequently, we chose to apply both parametric and nonparametric tests. Although we present the results of only parametric tests, in this study both statistical methods gave qualitatively the same answer.

Nicotine administration. Short- or long-term nicotine delivery was done by supplementing the drinking water with saccharin $(2 \%)$ and nicotine [experimental, nicotine tartrate (Sigma)] or with saccharin alone (control group). For short-term experiments, aged (24-month-old) CBA/J mice were given nicotine $(25 \mu \mathrm{g} / \mathrm{ml}$ on day $1,50 \mu \mathrm{g} / \mathrm{ml}$ on days $2-3,100 \mu \mathrm{g} / \mathrm{ml}$ on days $4-6$, and $200 \mu \mathrm{g} / \mathrm{ml}$ thereafter) for 6 weeks. The addition of nicotine to the drinking water resulted in an increase by two- to fourfold as measured by $\left[{ }^{3} \mathrm{H}\right]$ cytisine of the number of high-affinity $\left[{ }^{3} \mathrm{H}\right]$ nicotine binding sites in the brains of mice treated separately (data not shown), a result consistent with recent studies (Collins et al., 1996; Booker and Collins, 1997). For long-term exposure, CBA/J mice that were 14 months old were administered nicotine in their water as described above for 11 months before analysis. This age group was selected because preliminary examination of neuronal expression of $\mathrm{nAChR} \alpha 4$ immunoreactivity in these animals did not differ from that in the young age group (data not shown). In each group, the controls received no nicotine in the water. For all animals, at 4 weeks after nicotine administration, a small blood sample was collected from each animal to ensure nicotine uptake and metabolism by measuring for the presence of cotinine (STC Corporation, Bethlehem, PA). Although water administration of nicotine produces a less robust response than does direct infusion of the brain and the administration occurs principally at night when the animal is active and drinking (Collins et al., 1996; Booker and Collins, 1997), this regime may more closely resemble physiological administration than does direct infusion. For animals that received long-term nicotine, this method of administration presents a clear technical advantage over the methodology required to infuse nicotine directly into the brain.

\section{RESULTS}

\section{Anti-nAChR $\alpha \mathbf{4}$ antiserum subunit specificity}

The specificity of immunoreactivity of the rabbit anti-nAChR $\alpha 4$ antiserum (rabbits 5008 and 5009) has been addressed in previous studies (Rogers et al., 1991a,b, 1992; Flores et al., 1992, 1996; Cauley et al., 1996). These results include the absence of staining by preimmune serum, specific labeling of $\mathrm{nAChR} \alpha 4$ protein on Western blots and ELISA analysis, and specific immunoprecipitation of high-affinity $\left[{ }^{3} \mathrm{H}\right]$ cytisine binding sites (Flores et al., $1992,1996)$ but not receptors composed of $\alpha 3+\beta 2$ (Flores et al., 1992, 1996) (data not shown), $\alpha 2+\beta 2$ (Rogers et al., 1991b) (data not shown), or $\alpha 3+\beta 4$ (Flores et al., 1992, 1996) subunits. In addition, single-cell reverse transcription-PCR and immunocytochemical analysis of retinoic acid-differentiated $\mathrm{P} 19$ cells revealed the appearance of $\mathrm{nAChR} \alpha 4$ transcripts and immunoreactivity consistent with the appearance and presence of nAChR $\alpha 4$ RNA expression as well as high-affinity nicotine binding sites (Cauley et al., 1996).

For this study, the pattern of immunohistochemical staining was compared with the distribution of $\mathrm{nAChR} \alpha 4$ RNA measured by in situ hybridization or with the distribution of high-affinity $\left[{ }^{3} \mathrm{H}\right]$ nicotine binding sites in the mouse brain (Fig. 1). As noted above, nAChR $\alpha 4$ has a very distinct pattern of RNA expression relative to other closely related subunits, and it has been demonstrated to be a key participant in defining high-affinity $\left[{ }^{3} \mathrm{H}\right]$ nicotine or $\left[{ }^{3} \mathrm{H}\right]$ cytisine binding sites (Anand et al., 1991; Whiting et al., 1991; Flores et al., 1992, 1996). Consequently, the immunohistochemical staining pattern should be in close agreement with both these ligand binding studies and the RNA distribution (Fig. 1). The immunostaining pattern of anti-nAChR $\alpha 4$ displayed only a subset of the corresponding patterns of nAChR $\beta 2$ RNA (Deneris et al., 1988; Marks et al., 1992) or protein (Swanson et al., 1987; Hill et al., 1993) (data not shown) distribution as well as only a subset of the sites bound by $\left[{ }^{3} \mathrm{H}\right]$ epibatidine (Perry and Kellar, 1995; Marks et al., 1998). Immunoreactivity to nAChR $\alpha 4$ 


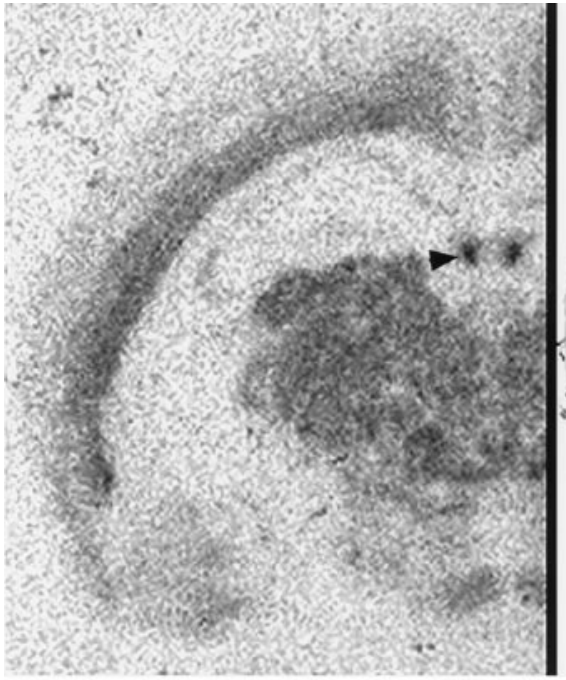

nAChRo4 RNA

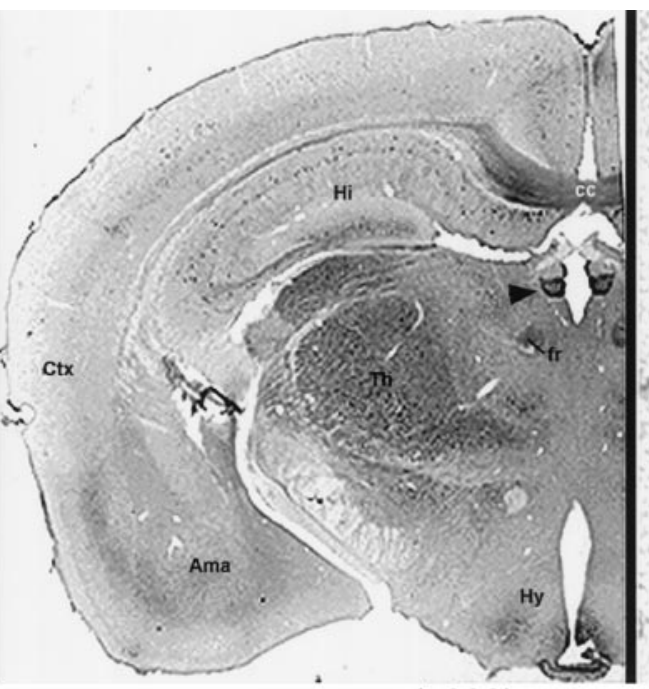

Anti-nAChRo4 (5009)

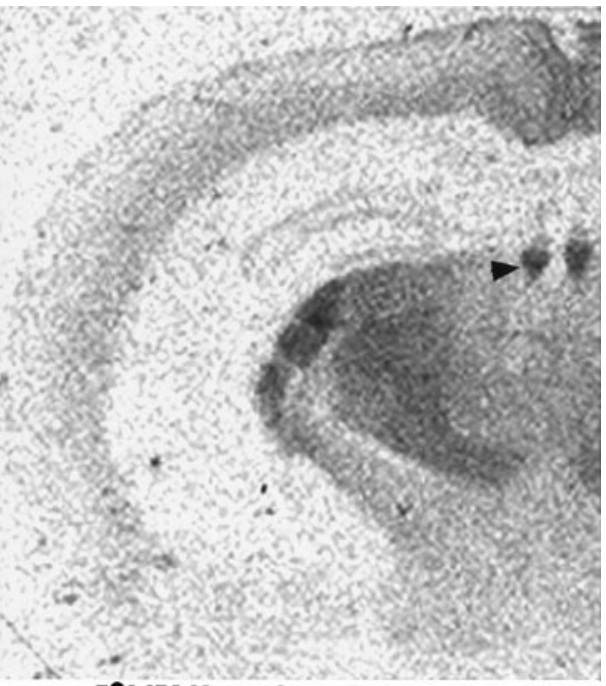

$\left[{ }^{3} \mathrm{H}\right]$ Nicotine Binding

Figure 1. Anti-nAChR $\alpha 4$ immunoreactivity (middle) corresponds with nAChR $\alpha 4$ RNA distribution (left) and $\left[{ }^{3} \mathrm{H}\right]$ nicotine binding (right). Mouse brains were prepared for in situ hybridization or $\left[{ }^{3} \mathrm{H}\right]$ nicotine binding as described previously (Marks et al., 1992). The coronal sections shown are from three different animals shown at approximately the same anatomical level. The arrowhead points to the medial habenula as an example of a region in which there is excellent agreement between all three methods. Other regions described in the text include the amygdala (Ama), corpus callosum ( $c c$ ), cortex $(C t x)$, fasciculus retroflexus $(f r)$, hippocampus $(H i)$, hypothalamus $(H y)$, and thalamus $(T h)$.

is in poor agreement with the distribution of ${ }^{125} \mathrm{I}$ - $\alpha$-bungarotoxin binding sites (Clarke et al., 1985; Marks et al., 1985).

Some discrepancies between these independent measures of $\mathrm{nAChR} \alpha 4$ were noted, but they may reflect protein transport from the cell soma to more distal nuclei. For example, in the striatum, both RNA (Marks et al., 1992) and immunoreactivity are detected in the globus pallidus, but the majority of $\left[{ }^{3} \mathrm{H}\right]$ nicotine binding is present in the caudate putamen. This is similar to the interpeduncular nucleus (IPN) where the in situ hybridization signal is conspicuously less than the strong $\left[{ }^{3} \mathrm{H}\right]$ nicotine binding (Marks et al., 1992). Anti-nAChR $\alpha 4$ immunoreactivity was also strong in this region (data not shown) but diff use, consistent with localization in process terminals and electrophysiological studies (Lena et al., 1993). This is also supported by the strong antinAChR $\alpha 4$ immunoreactivity found in the cell bodies of the medial habenula and the processes in the habenular-IPN pathway that extend via the fasciculus retroflexus (data not shown). In other regions (see Fig. 1), the nuclei of the lateral hypothalamic region and the amygdala contain RNA and anti-nAChR $\alpha 4$ staining but little or no $\left[{ }^{3} \mathrm{H}\right]$ nicotine binding. This may reflect the sensitivity in detecting $\left[{ }^{3} \mathrm{H}\right]$ ligand binding or the possibility that $\mathrm{nAChR} \alpha 4$ forms a receptor with other subunits that do not favor high-affinity $\left[{ }^{3} \mathrm{H}\right]$ ligand binding. However, given the likelihood of transport of $\mathrm{nAChR} \alpha 4$ protein, there was overall agreement between these independent measures of $\mathrm{nAChR} \alpha 4$ expression.

\section{Anti- $\alpha 4$ immunoreactivity in the brain of young and aged CBA/J mice}

This study focuses on anti-nAChR $\alpha 4$ immunostaining in five major anatomically distinguishable regions of the mouse brain: the globus pallidus, medial septum, diagonal band (also termed the triangular septal region) (Marks et al., 1992), hippocampus (occasional neurons of the stratum oriens, CA1, and the polymorphic region of the dentate gyrus [PoDG] [see Franklin and Paxinos (1997) for definition]), and the substantia nigra. These regions were selected because they are anatomically well defined, they exhibit prominent anti- $\alpha 4$ immunoreactivity in the soma of resident neurons, and changes in the expression of cholinergic system markers such as acetylcholinesterase or choline acetyltransferase have been reported to occur in some, but not all, of these regions in the aging mammalian brain (Araujo et al., 1988, 1990). Furthermore, diminished expression of $\left[{ }^{3} \mathrm{H}\right]$ nicotine binding sites and response to nicotine administration in the aged mammalian brain, particularly in basal forebrain structures, are well established for both the human and rodent brain (Whitehouse et al., 1986, 1988; Kellar et al., 1987, 1989; Zhang et al., 1990; Shroder et al., 1991).

Typical results for young and aged animals of $\mathrm{nAChR} \alpha 4$ immunohistochemical localization in the regions examined are shown in Figure 2. In all cases, $25 \mu \mathrm{m}$ sections collected at $125 \mu \mathrm{m}$ intervals from the brains of 13 young mice (3-5 months old; five males and eight females) or 15 aged mice (24-28 months old; seven males and eight females) were examined. Quantitative analyses of staining are presented in Figure 3. Overall, there were no differences between the average number of immunopositive neurons detected in young and aged $\mathrm{CBA} / \mathrm{J}$ mice in the globus pallidus and the substantia nigra (staining was dominant in the pars compacta but was present in occasional cell bodies of the pars reticulata). A statistically significant decrease $(p<0.05)$ in the number of immunopositive neurons was detected in the medial septum and diagonal band in aged mice relative to young animals. These regions were, however, notable for the considerable variability in the number of stained neurons between individuals of the same age, and it was common to find a twofold difference in the number of immunopositive cells. This was particularly evident in the diagonal band of aged animals, where staining ranged from the typical nearly undetectable signal (Fig. 2) to one notable male animal that exhibited immunostaining that was indistinguishable from young mice (data not shown). This single aged animal suggests either that animals with reduced staining in this region tended to be enriched in our aged population or that some animals fail to exhibit diminished $\mathrm{nAChR} \alpha 4$ immunoreactivity with age. More animals or a systematic study of 


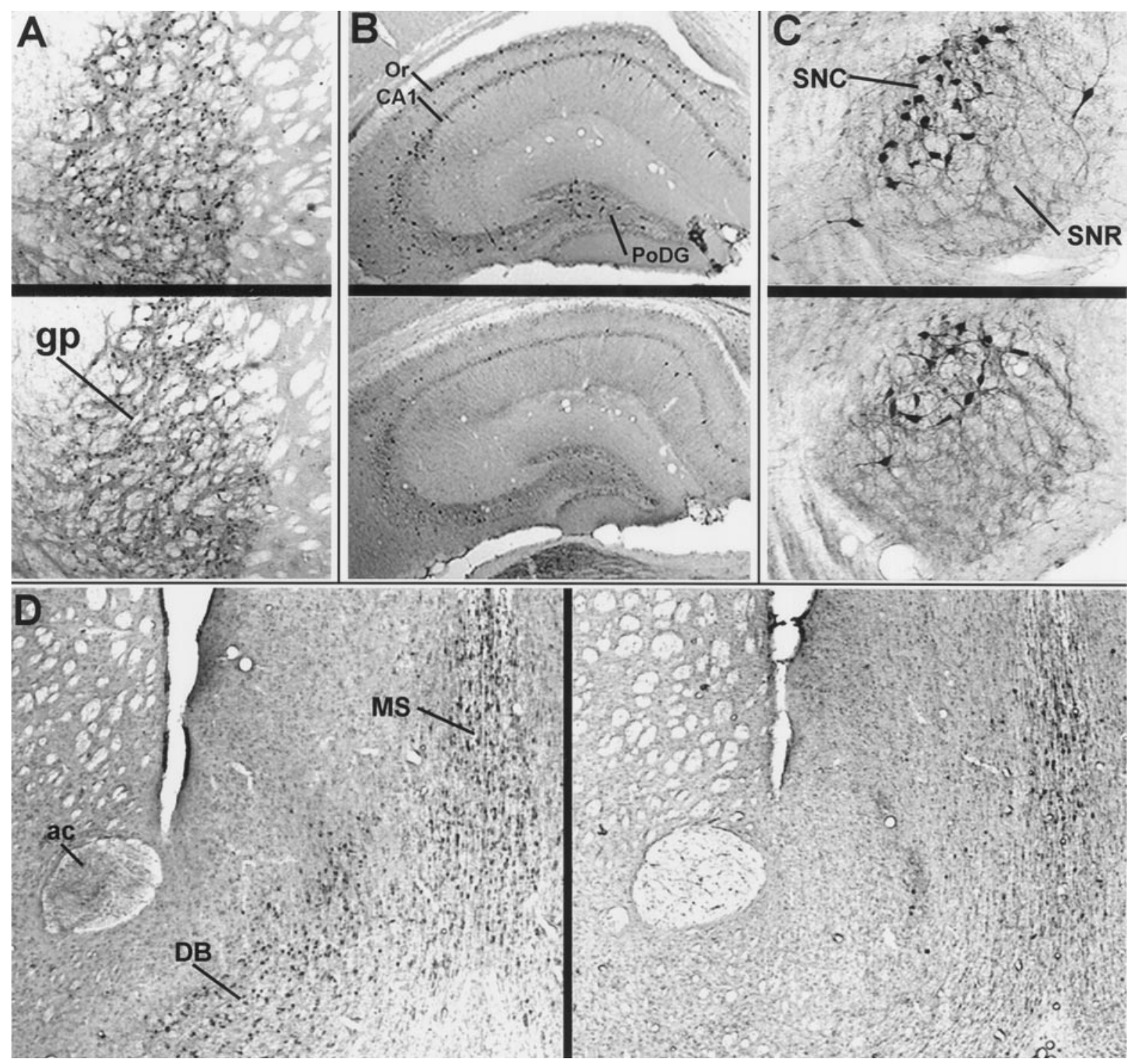

Figure 2. Comparison of anti-nAChR $\alpha 4$ immunoreactivity in five brain regions of young or aged CBA/J mice. Anti-nAChR $\alpha 4$ antisera reveal putative neuronal cell staining in representative brain sections taken from a young $(A-C$, upper; $D$, left $)$ or aged $(A-C$, lower; $D$, right $)$ CBA/J male mouse. The regions emphasized are the globus pallidus ( $g p)$ in $A$; the hippocampus [CA1, the polymorphic layer of the dentate gyrus, and the stratum oriens $(O r)]$ in $B$; the substantia nigra [compacta $(S N C)$ and reticulata $(S N R)]$ in $C$; and the medial septum $(M S)$, diagonal band $(D B)$, and anterior commissure $(a c)$ in $D$.

the animal population during aging will be required to distinguish unambiguously between these possibilities.

Changes in anti-nAChR $\alpha 4$ neuronal immunostaining in the hippocampus were conspicuous between young and aged groups. As shown in Figure 2 and with greater magnification in Figure 4, columns 1 and 2, immunoreactivity was restricted to a small number of neurons in CA1 that were mostly in association with the inner or outer margin of the CA1 pyramidal cell layer, the dorsal margin of the stratum oriens, and the PoDG. Stained neurons in the PoDG were greatly diminished in the aged brain, as will be discussed in greater detail below. The stained cells of CA1 occurred predominantly as solitary neurons, but in certain sections they could be observed as evenly spaced groups of three to six. In all young animals, these neurons were distinguished by prominent processes that extended through the entire stratum radiatum and the lacunosum molecular layer of the hippocampal field (Fig. 4, column 1). These processes also exhibit prominent and regularly spaced varicosities, giving them a bead-on-a-string appearance (Fig. 4, column 1, bottom row). Both processes and varicosities were essentially absent from the hippocampus of all aged animals (Fig. 4, compare columns 1 and 2, bottom row). In the stratum oriens, a distinct population of neurons distinguished by prominent processes that extended laterally was present in young animals but absent in aged mice.

Comparison of males and females within the young or aged groups revealed one statistically significant difference. In the CA1 region of the hippocampus, the number of immunopositive neurons was significantly greater $(p<0.01)$ in young males relative to young females (Fig. 3). This difference was restricted to the CA1 region, and it was not observed in the stratum oriens or PoDG (data not shown). This sex-related difference did not occur in the aged animal group. Although other regions did not exhibit a sex-related difference in expression, the loss of $\mathrm{nAChR} \alpha 4$ immunopositive neurons found in aged animals was driven pre- 


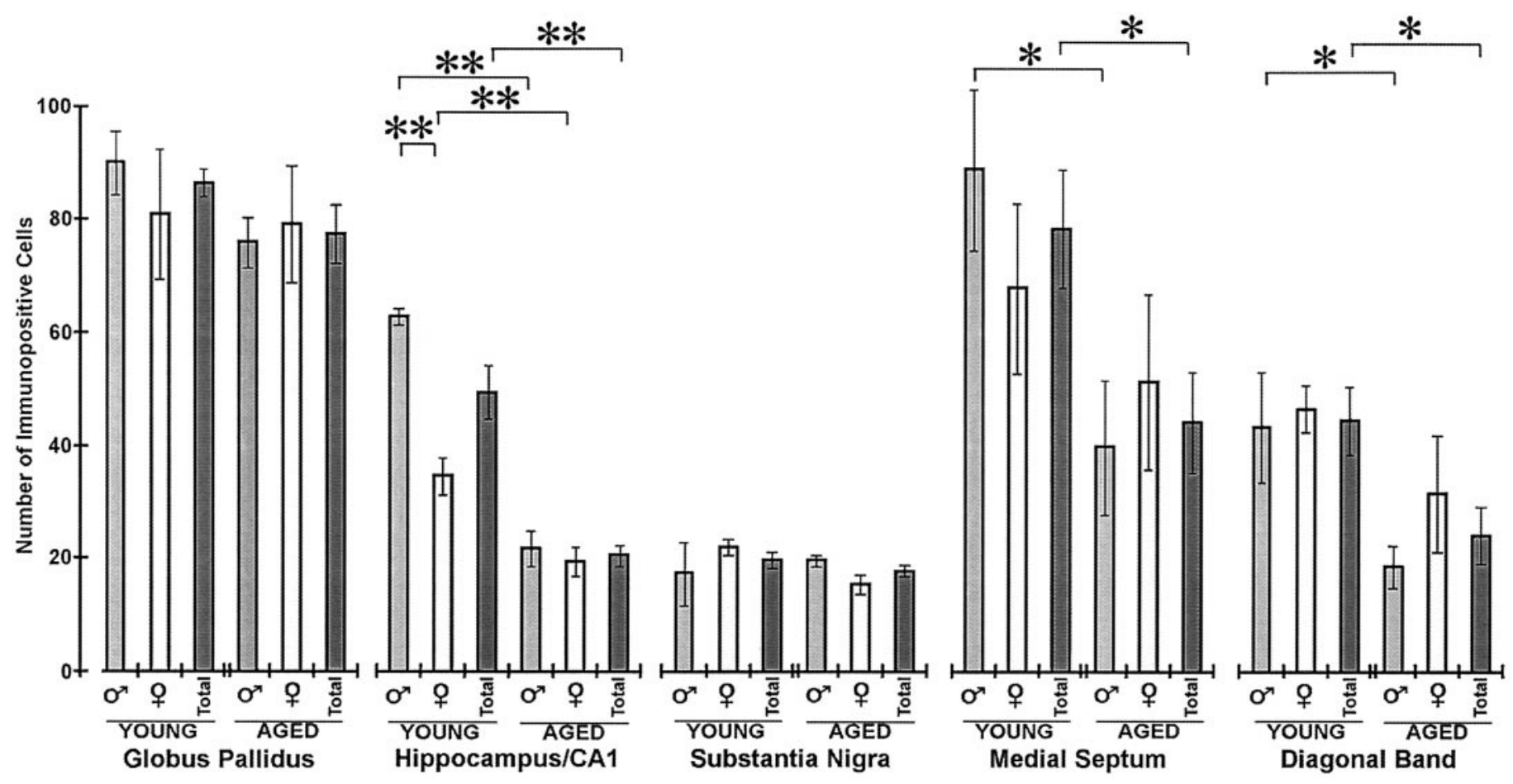

Figure 3. Quantitative analysis of anti-nAChR $\alpha 4$ immunoreactivity in young and aged CBA/J mice. The data from sections such as those shown in Figure 2 were compiled from 13 young (3-5 months old; five males and eight females) or 15 aged (24-28 months old; seven males and eight females) $\mathrm{CBA} / \mathrm{J}$ mice as described in the text. The results are grouped to show the mean immunopositive cell number ( \pm SEM) for each region by age and by sex (males, light gray box; females, open box) and the average for the group (dark gray box). Brackets define $t$ test pairs in which the results were statistically significant $(* p<0.05$ level; $* * p<0.01)$.

dominantly by the strong loss of immunopositive cells in males as shown in Figure 3. This was observed for the medial septum and the diagonal band, where the decrease in immunoreactivity was greatest between young and aged males, but the decline in immunopositive cells between young and aged females was not statistically different. Although both sexes exhibited a substantial decrease in hippocampal $\mathrm{nAChR} \alpha 4$-expressing neurons in aged animals (Fig. 3), this decline was approximately fourfold in males compared with a less than twofold decrease in females.

\section{Long-term, but not short-term, nicotine administration alters age-related changes in $\mathrm{nAChR} \alpha 4$ immunoreactivity in the hippocampus}

The administration of nicotine to rodents results in the well established increased in expression of high-affinity $\left[{ }^{3} \mathrm{H}\right]$ nicotine binding sites in the brain (Marks et al., 1985, 1991, 1992; Kellar et al., 1989; Flores et al., 1992). Because of the dramatic age-related decrease in the expression of anti-nAChR $\alpha 4$-immunopositive cells in the hippocampus, we tested the possibility that the oral administration of nicotine to age- and sex-matched CBA/J mice would modify nAChR $\alpha 4$ neuronal expression in aged mice. This was tested in male mice because of the pronounced difference observed in staining between young animals relative to aged ones (Fig. 3). The experimental groups were as follows. First, 24month-old CBA/J male mice were divided into two groups of three animals each, and one group was administered nicotine in their water for a period of 6 weeks (short-term); the other group received no nicotine. Second, another group consisted of 14month-old $\mathrm{CBA} / \mathrm{J}$ male mice that were placed on either water with saccharin or water with saccharin and nicotine for a period of 11 months (long-term, see Materials and Methods). As shown in Figures 4, column 3, and 5, aged mice administered nicotine for 6 weeks exhibited no change in anti-nAChR $\alpha 4$-immunopositive cells relative to aged mice controls that did not receive nicotine. In contrast, 14-month-old CBA/J mice given nicotine orally for 11 months exhibited notable differences in anti-nAChR $\alpha 4$ immunoreactivity relative to controls (Fig. 5). Immunopositive neurons of the PoDG region were retained when compared with aged controls not receiving nicotine, and the number of immunopositive cells did not differ significantly from that in young animals (Figs. $4,5)$. Conversely, there was an almost complete loss of immunopositive cell staining in the stratum oriens and in the CA1 region, where the number of labeled cells diminished similarly to that in aged animals not given nicotine or those aged animals that received nicotine for 6 weeks (Figs. 4, column 4, middle row, 5). Despite the loss of neuronal staining in CA1, there was a notable difference between the subcellular distribution of anti-nAChR $\alpha 4$ immunoreactivity in long-term nicotine-treated animals relative to controls. As seen in Figure 4, column 4, bottom row, the presence of long dendritic-like processes complete with varicosities seen in young animals was retained in the adult mice receiving 11 month nicotine administration. Similar immunoreactivity in the processes originating from neurons of the CA1 in aged animals given nicotine for only 6 weeks was absent (Fig. 4, column 3 , middle row). Notably, the neurons and their processes that exhibit these varicosities resemble closely the neurons in the hippocampus identified by Alkondon et al. (1997) to express to $\mathrm{nAChR} \alpha 4 \beta 2$-type receptors and regulate GABA release. The examination of the globus pallidus and substantia nigra from both of these groups exhibited no quantitative difference in immu- 


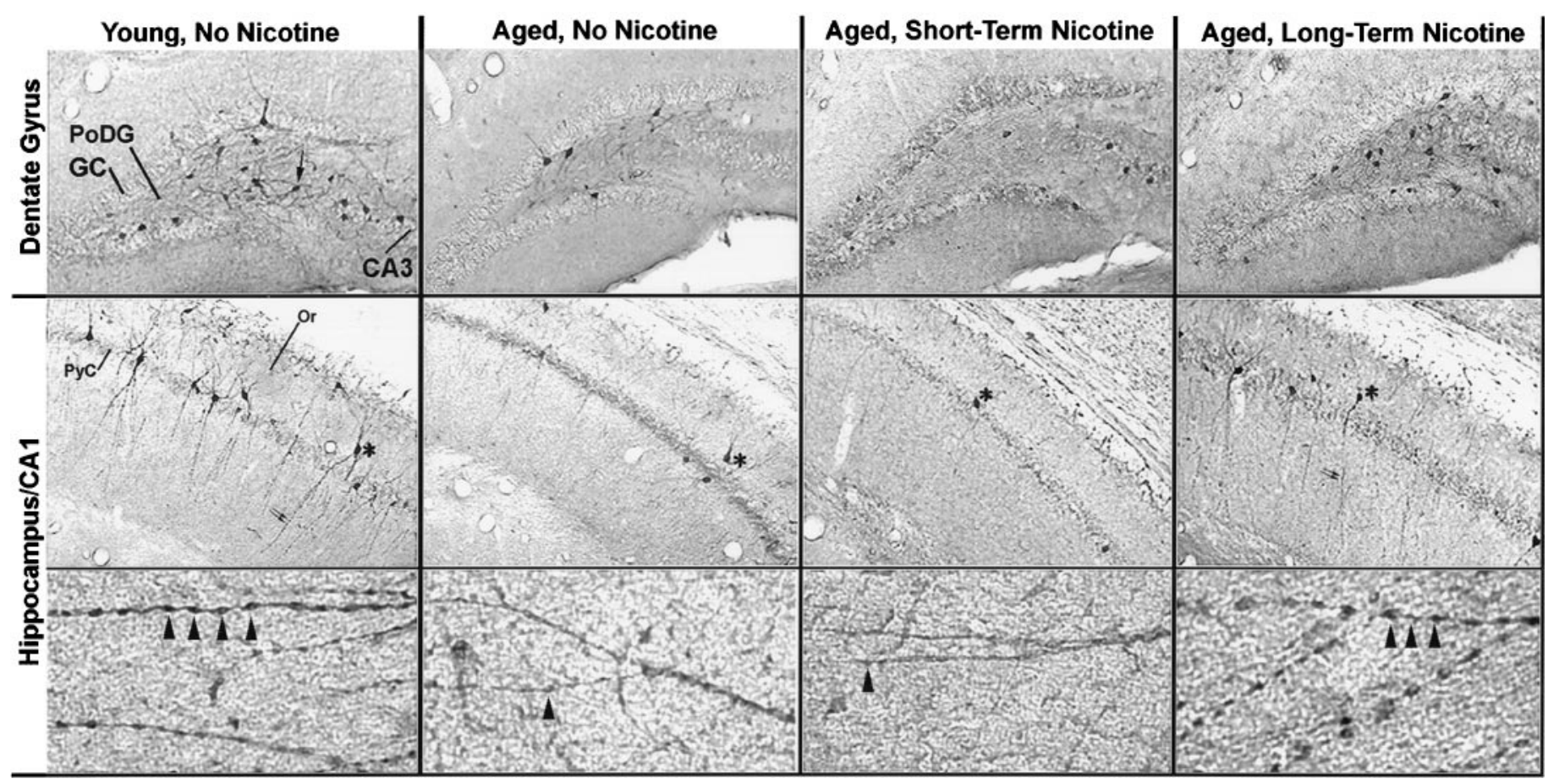

Figure 4. Anti- $\alpha 4$ immunoreactivity in hippocampal sections from representative young and aged male CBA/J mice that were grouped according to receiving no nicotine (control) or nicotine in their water for 6 weeks (short-term) or 11 months (long-term). As described in Materials and Methods, three male CBA/J mice were given nicotine and saccharin in their water for 6 weeks (24 months old at start of treatment) or 11 months (14 months old at start of treatment). Controls received water with saccharin but without nicotine. In the top row is a representative section from the dentate gyrus of each group exhibiting the immunoreactivity of neurons to anti-nAChR $\alpha 4$ antibodies. The arrow (left) points to a stained neuron in the polymorphic layer. Other labels show the granule cells $(G C)$ of the dentate gyrus and neurons of the CA3. In the middle row is shown the hippocampal CA1 region for each group. The asterisks note an anti-nAChR $\alpha 4$-immunopositive cell in each treatment group. The pyramidal cell layer $(P y C)$ and the $\mathrm{Or}$ are noted. The bottom row shows at high magnification the immunopositive processes that extend ventrally from stained cells of the CA1 (middle row). These cells exhibit extensive dendritic-like processes that exhibit regular varicosities on greater magnification (arrowheads). A typical young animal (3 months) is shown on the left; a typical older animal (25 months) is shown on the right. These cells are less abundant, and the large processes exhibiting varicosities are diminished or entirely absent in the older animals except in the aged group that was supplied with nicotine in their water for 11 months.

nopositive cells compared with that in aged-matched controls or in young animals (data not shown).

\section{DISCUSSION}

The expression of $\mathrm{nAChR} \alpha 4$ immunoreactivity in the brain of young and aged CBA/J mice was examined, and it was determined whether short- or long-term nicotine administration alters patterns of expression. Rabbit polyclonal antiserum with specificity to $\mathrm{nAChR} \alpha 4$ revealed a pattern of immunostaining that closely resembles that of RNA expression for this subunit and of high-affinity $\left[{ }^{3} \mathrm{H}\right]$ nicotine binding. We selected the $\mathrm{CBA} / \mathrm{J}$ mouse because of both availability and the observation in preliminary studies that this strain had particularly robust neuronal staining for this subunit. Other strains, including DBA/2 or $\mathrm{C} 57 \mathrm{Bl} / 6$, exhibited relatively poor immunoreactivity to $\mathrm{nAChR} \alpha 4$ (data not shown). The well documented difference between strains (e.g., Marks et al., 1991) with respect to high-affinity $\left[{ }^{3} \mathrm{H}\right]$ nicotine binding and sensitivity in behavioral tests to nicotine (Marks et al., 1991) suggests that considerable variation in anti-nAChR $\alpha 4$ immunoreactivity could be expected, but this remains to be thoroughly examined. If true, however, strain selection for studying the influence of aging on nicotinic receptors will be critical. In the CBA/J mice selected for this study, anti-nAChR $\alpha 4$ immunoreactivity was localized to both putative axonal and dendritic processes of discrete neuronal populations. Anti-nAChR $\alpha 4$ immunoreactivity was diminished in aged animals in many, but not all, regions of the brain. Specifically, the loss of immunoreactivity was notable in the medial septum and diagonal band, and it was dramatic in the hippocampus.

When aged male $\mathrm{CBA} / \mathrm{J}$ mice were given nicotine in their water for 6 weeks, the loss of immunoreactivity was not reversed. In contrast, administration of nicotine to adult mice for at least 11 months seemed to preserve neuronal staining in the polymorphic layer of the dentate gyrus but not in the hippocampal CA1 region. Nevertheless, neurons of the CA1 region that exhibited immunoreactivity also retained strong staining of their processes that was not observed in any other aged animal group. This result suggests that long-term nicotine administration may have very specific and highly selective regional effects on various neuronal populations. Furthermore, this result suggests that these effects may not be manifested via simple mechanisms of receptor upregulation, because this occurs in mice within $10 \mathrm{~d}$ of oral nicotine delivery (Collins et al., 1996; Booker and Collins, 1997) (data not shown). An interesting possibility is that long-term administration may enhance or alter synaptic connectivity, resulting in the retention of immunopositive neurons.

Despite the evidence of $\mathrm{nAChR}$ decline in aging and perhaps in more severe diseases of neurodegeneration, it remains controversial as to how this excitatory system could exert its effect on the brain. One likely possibility is that $\mathrm{nAChRs}$ exert the majority of their effect presynaptically, possibly via modulation of release of neurotransmitters such as dopamine or GABA (Grady et al., 1992; Lena et al., 1993; McGhee et al., 1995; Bertolino et al., 

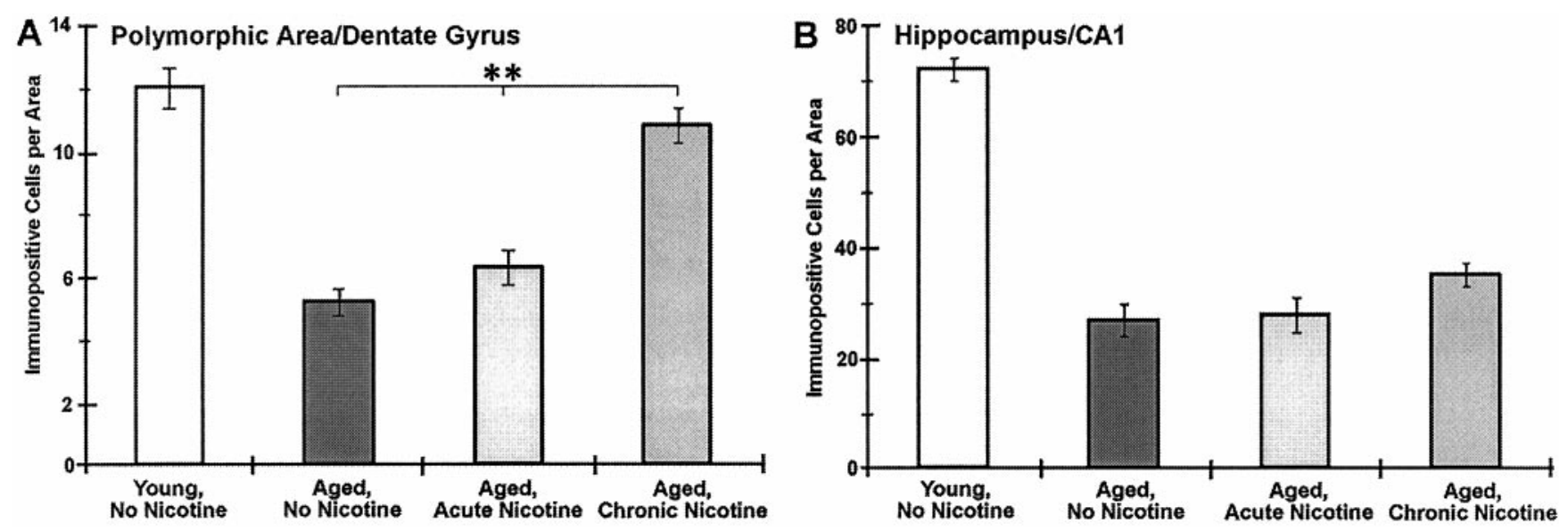

Figure 5. Quantitative analysis of anti-nAChR $\alpha 4$ immunoreactivity between young and aged CBA/J mice given nicotine in their water for 6 weeks or 11 months. The number of neurons stained for $\mathrm{nAChR} \alpha 4$ immunoreactivity in the designated region was obtained from sections such as those shown in Figure 4 and was compiled from three mice in each group as described in the text. Error bars reflect the mean number $( \pm$ SEM) of immunopositive cells in each region counted from at least eight sections for each animal. $A$, Stained neurons in the polymorphic area of the dentate gyrus from 25-month-old mice that were supplied nicotine for 11 months (chronic) versus aged mice (24-27 months old) either not given nicotine or administered nicotine for only 6 weeks (acute) were counted. The double asterisks denote a significant difference $(p<0.01)$. $B$, The number of immunopositive neurons observed in the CA1 region of each group was similarly scored. A significant decrease in the number of stained neurons in all aged groups relative to young animals $(p<0.01)$ was observed in this region of the hippocampus (see text).

1997; Wonnacott, 1997). Consequently, the hypothesis has been advanced that relatively small numbers of nAChRs placed at key regulatory synapses could be crucial in regulating or modulating the concentration of neurotransmitter during synaptic activation. Our antibodies can address this issue only indirectly because they were prepared to a cytoplasmic domain of $\mathrm{nAChR} \alpha 4$ and consequently they do not necessarily discriminate between mature and assembling receptors. In general, axons are difficult to identify without double labeling, but the staining of processes in some white-matter tracts [e.g., the anterior commissure (see Fig. 2) and the fasciculus retroflexus (data not shown)] in young animals is consistent with substantial axonal transport and presynaptic localization. This staining was diminished or absent in aged animals (see Fig. 2; data not shown). The immunostaining of the prominent processes extending from cells of the hippocampal CA1 region and the presence of varicosities in young animals suggest a more somal and dendritic localization in these cells. In any case, the prominence of $\mathrm{nAChR} \alpha 4$ immunoreactivity in neurons and their location (e.g., thalamus, neostriatal pathway, and the cells of the PoDG) are consistent with the location and shape of cells generally described as dopaminergic neurons or inhibitory interneurons. The similarity of morphology between these neurons with GAD-staining neurons (data not shown) and the recently described GABA-responsive neurons in the hippocampus using electrophysiology and dye-fill experiments (Aarne et al., 1994; Geula and Mesulam, 1994; Alkondon et al., 1997; Bertolino et al., 1997) also suggests that these cells could be inhibitory. In any case, their relatively infrequent but regular distribution suggests that these neurons could play an important role in regulating excitation in the hippocampus, particularly via modulation of GABA release (Alkondon et al., 1997), and their loss could seriously alter this balance of local synaptic transmission. Consequently, the region- and cell-specific loss of $\mathrm{nAChR} \alpha 4$ immunoreactivity during aging could have profound effects on retaining the critical balance between excitation and inhibition in key brain regions that are subject to failure and neurodegeneration with age. The retention of these neurons in a nondysfunctional state, which seems to be the effect of long-term nicotine application, would likely slow the onset of such processes.

Despite the significant limits of using the aging-mouse model to understand age-related neurodegenerative diseases in humans, these results may provide some insight into the mechanisms through which chronic nicotine administration by smoking might lead to the slowing of the onset of Parkinson's disease or senile dementia of the Alzheimer's type (vanDuijn and Hofman, 1991; vanDuijn et al., 1991; Morens et al., 1994; Nicholson, 1994). In particular, whether the neurons that express these markers die or whether they become dysfunctional in their expression with age remains a question to be resolved. In humans, the depletion of ChAT via neuronal loss in the basal forebrain seems to be a contributor to Alzheimer's disease (Geula and Mesulam, 1994), but in the cortex this loss is greater than can be accounted for by neuronal loss (Geula and Mesulam, 1994). In this study, both in the hippocampus (where the most dramatic changes in nAChR $\alpha 4$-immunopositive cells were observed) and in the diagonal band (data not shown), the administration of nicotine to aged animals was in general not effective in recovering or deterring the loss of stained neurons except in the polymorphic layer of the dentate gyrus. Nevertheless, there was a dramatic retention of immunopositive processes complete with varicosities in the immunopositive neurons that remained that were not present in the other aged-mouse groups. However, this retention of expression required nicotine administration for $\sim 11$ months of a 25 month life span of these mice and was initiated before nAChR $\alpha 4$ expression decline. Consequently, these data support the notion that nicotine exerts a positive influence in the aged animal via promoting the retention of neuronal connections that are normally lost during normal aging but does so only if supplied in advance for a prolonged period before the onset of age-related cholinergic neuronal decline.

\section{REFERENCES}

Aarne AS, Ylinen M, Penttonen M, Buzsaki G (1994) Inhibitory CA1CA3-hilar region feedback in the hippocampus. Science 265:1722-1724. 
Alkondon M, Pereira EFR, Barbosa CTF, Albuquerque EX (1997) Neuronal nicotinic acetylcholine receptor activation modulates $\gamma$-aminobutyric acid release from CA1 neurons of rat hippocampal slices. J Pharmacol Exp Ther 283:1396-1411.

Anand R, Conroy WG, Schoepfer R, Whiting P, Lindstrom J (1991) Neuronal nicotinic acetylcholine receptors expressed in Xenopus oocytes have a pentameric quaternary structure. J Biol Chem 266:11192-11198.

Araujo DM, Lapchak PA, Robitaille Y, Gauthier S, Quirion R (1988) Differential alteration of various cholinergic markers in cortical and subcortical regions of human brain in Alzheimer's disease. J Neurochem 50:1914-1923.

Araujo DM, Lapchak PA, Meaney MJ, Collier B, Quirion R (1990) Effects of aging on nicotinic and muscarinic autoreceptors function in the rat brain: relationship to presynaptic cholinergic markers and binding sites. J Neurosci 10:3069-3078.

Bertolino M, Kellar KJ, Vicini S, Gillis RA (1997) Nicotinic receptor mediates spontaneous GABA release in the rat dorsal motor nucleus of the vagus. Neuroscience 79:671-681.

Booker TK, Collins AC (1997) Long-term ethanol treatment elicits changes in nicotinic receptor binding in only a few brain regions. Alcohol 14:131-140.

Boulter J, Connolly J, Deneris E, Goldman D, Heinemann S, Patrick J (1987) Functional expression of two neuronal nicotinic acetylcholine receptors from cDNA clones identifies a gene family. Proc Natl Acad Sci USA 84:7763-7768.

Cauley K, Marks M, Gahring LC, Rogers SW (1996) Neuronal nicotinic receptor genes $\alpha 3, \alpha 4$ and $\beta 2$ and high affinity nicotine binding sites are expressed by P19 embryonal carcinoma cells. J Neurobiol 30:303-314.

Clarke PBS, Schwartz RD, Paul SM, Pert CB, Pert A (1985) Nicotine binding in the rat brain: autoradiographic comparison of $\left[{ }^{3} \mathrm{H}\right]$ acetylcholine, $\left[{ }^{3} \mathrm{H}\right]$ nicotine, and ${ }^{125} \mathrm{I}-\alpha$-bungarotoxin. J Neurosci 5:1307-1315.

Collins AC, Wilkins LH, Slobe BS, Cao JZ, Bullock AE (1996) Longterm ethanol and nicotine treatment elicit tolerance to ethanol. Alcohol Clin Exp Res 20:990-999.

Deneris ES, Connolly J, Boulter J, Wada E, Wada K, Swanson L, Patrick J, Heinemann S (1988) Primary structure and expression of $\beta 2$ : a novel subunit of neuronal nicotinic acetylcholine receptors. Neuron 1:45-54.

Deneris ES, Connolly J, Rogers SW, Duvoisin R (1991) Pharmacological and functional diversity of neuronal nicotinic acetylcholine receptors. Trends Pharmacol 12:34-40.

Elgoyhen AB, Johnson DS, Boulter J, Vetter DE, Heinemann S (1994) Alpha 9: an acetylcholine receptor with novel pharmacological properties expressed in rat cochlear hair cells. Cell 79:705-715.

Flood DG, Coleman PD (1996) Neuron numbers and sizes in aging brain: comparisons of human, monkey and rodent data. Neurobiol Aging 9:453-463.

Flores CM, Rogers SW, Pabreza L, Wolf B, Kellar KJ (1992) Immunoprecipitation and characterization of the high affinity nicotine binding site in the brain. Mol Pharmacol 41:31-37.

Flores CM, DeCamp RM, Kilo S, Rogers SW, Hargreaves KM (1996) Neuronal nicotinic receptor expression in sensory neurons of the rat trigeminal ganglion: demonstration of $\alpha 3 \beta 4$, a novel subtype in the mammalian nervous system. J Neurosci 16:7892-7901.

Franklin KJB, Paxinos G (1997) The mouse brain. New York: Academic.

Gahring LC, Carlson NG, Kulmer R, Rogers SW (1996) Neuronal expression of tumor necrosis factor alpha in the murine brain. Neuroimmunomodulation 3:289-303.

Geula C, Mesulam M-M (1994) Cholinergic systems and related neuropathological predilection patterns in Alzheimer disease. In: Alzheimer disease (Terry RD, Katzman R, Bick KL, eds), pp 263-291. New York: Raven.

Giacobini E (1992) Nicotine acetylcholine receptors in human cortex: aging and Alzheimer's disease. In: Biology of nicotine (Lippiello PM, Collins AC, Gray AC, Robinson JH, eds), pp 183-215. New York: Raven.

Grady S, Marks MJ, Wonnacott S, Collins AC (1992) Characterization of nicotinic receptor-mediated $\left[{ }^{3} \mathrm{H}\right]$ dopamine release from synaptosomes prepared from mouse striatum. J Neurochem 59:848-856.

Hill JA, Zoli M, Bourgeois J-P, Changeux JP (1993) Immunocytochemical localization of a neuronal nicotinic receptor: the $\beta 2$-subunit. J Neurosci 13:1551-1568.

Kellar KJ, Whitehouse PJ, Martino-Barrows AM, Marcus K, Price DL (1987) Muscarinic and nicotinic cholinergic binding sites in Alzheimer's disease. Brain Res 436:62-68.

Kellar KJ, Giblin BA, Lumpkin MD (1989) Regulation of brain cholinergic sites by nicotine. Prog Brain Res 79:209-216.
Lena C, Changeux JP, Mulle C (1993) Evidence for "preterminal" nicotinic receptors on GABAergic axons in the rat interpeduncular nucleus. J Neurosci 13:2680-2688.

Lindstrom J (1996) Neuronal nicotinic acetylcholine receptors. In: Ion channels (Narahashi N, ed), pp 377-450. New York: Plenum.

Marks MJ, Stitzel JA, Collins AC (1985) Time course study of the effects of chronic nicotine infusion on drug response and brain receptors. J Pharmacol Exp Ther 235:619-628.

Marks MJ, Campbell SM, Romm E, Collins AC (1991) Genotype influences the development of tolerance to nicotine in the mouse. J Pharmacol Exp Ther 259:392-402.

Marks MJ, Pauly JR, Gross SD, Deneris ES, Hermans-Borgmeyer I, Heinemann S, Collins AC (1992) Nicotine binding and nicotinic receptor RNA after chronic nicotine treatment. J Neurosci 12:2765-2784.

Marks MJ, Smith KW, Collins AC (1998) Differential agonist inhibition identifies multiple epibatidine binding sites in mouse brain. J Pharmacol Exp Ther 285:377-386.

McGhee DS, Heath MJS, Gelber S, Devay P, Role LW (1995) Nicotine enhancement of fast excitatory synaptic transmission in CNS by presynaptic receptors. Science 269:1692-1696.

Morens DM, Grandinetti A, Reed D, White LR (1994) Smokingassociated protection from Alzheimer's and Parkinson's disease. Lancet 343:356-357.

Nicholson D (1994) Anti-dementia agents: research and prospects for therapy. In: Neuroscience perspectives (Jenner P, ed). San Diego: Academic.

Peng X, Gerzanich V, Anand R, Lindstrom J (1997) Chronic nicotine treatment up-regulates alpha3 and alpha7 acetylcholine receptor subtypes expressed by the human neuroblastoma cell line SH-SY5Y. Mol Pharmacol 51:776-784.

Perry DC, Kellar KJ (1995) [ $\left.{ }^{3} \mathrm{H}\right]$ Epibatidine labels nicotinic receptors in rat brain: an autoradiography study. J Pharmacol Exp Ther 275:1030-1034.

Rogers SW, Gahring LC, Papke RP, Heinemann S (1991a) Identification of cultured cells expressing ligand-gated cationic channels. Protein Expr Purif 2:108-116.

Rogers SW, Hughes T, Hollmann M, Gassic G, Deneris E, Heinemann S (1991b) The characterization and localization of the glutamate receptor subunit, GluR1, in the rat brain. J Neurosci 11:2713-2724.

Rogers SW, Mandelzys A, Deneris E, Cooper E, Heinemann S (1992) The expression of nicotinic acetylcholine receptors by PC12 cells treated with NGF. J Neurosci 12:4611-4623.

Sargent P (1993) Neuronal nicotinic acetylcholine receptors. Annu Rev Neurosci 16:403-443.

Schulz DW, Kuchel GA, Zigmond RE (1993) Decline in response to nicotine in aged rat striatum: correlation with a decrease in a subpopulation of nicotinic receptors. J Neurochem 61:2225-2232.

Shroder H, Giacobini E, Struble RG, Zilles K, Maelicke A (1991) Nicotine cholinoceptive neurons of the frontal cortex are reduced in Alzheimer's disease. Neurobiol Aging 12:259-262.

Swanson L, Simmons D, Whiting P, Lindstrom J (1987) Immunohistochemical localization of neuronal nicotinic receptors in the rodent central nervous system. J Neurosci 7:3334-3342.

vanDuijn CM, Hofman A (1991) Relation between nicotine intake and Alzheimer's disease. Br Med J 302:1491-1494.

vanDuijn CM, Stijnen T, Hofman A (1991) Risk factors for Alzheimer's disease: overview of the EURODEM collaborative re-analysis of casecontrol studies. EURODEM risk factors research group. Int J Epidem 20:S48-S57.

Whitehouse PJ, Martino AM, Antuono PG, Lowenstein PR, Coyle JT, Price DL, Kellar KJ (1986) Nicotinic acetylcholine binding sites in Alzheimer's disease. Brain Res 371:146-151.

Whitehouse PJ, Martino AM, Wagster MV, Price DL, Mayeux R, Atack JR, Kellar KJ (1988) Reductions in $\left[{ }^{3} \mathrm{H}\right]$ nicotinic acetylcholine binding in Alzheimer's disease and Parkinson's disease: an autoradiography study. Neurology 38:720-723.

Whiting P, Schoepfer R, Lindstrom J, Priestly T (1991) Structural and pharmacological characterization of the major brain nicotinic acetylcholine receptor subtype stably expressed in mouse fibroblasts. Mol Pharmacol 40:463-472.

Wonnacott S (1997) Presynaptic nicotinic acetylcholine receptors. Trends Neurosci 20:92-98.

Zhang X, Wahlstrom G, Nordberg A (1990) Influence of development and aging on nicotinic receptor subtypes in rodent brain. Int J Dev Neurosci 8:715-721. 